
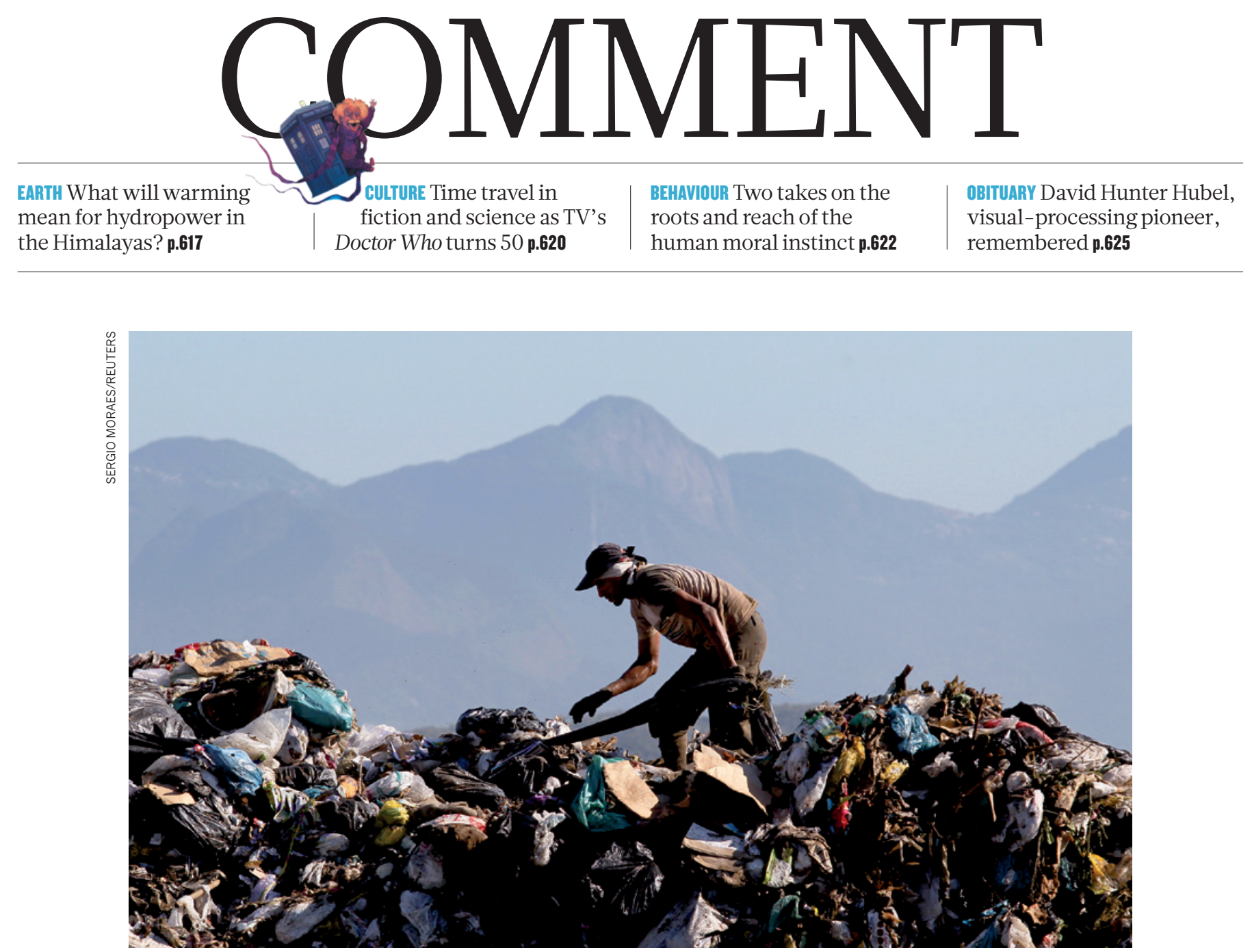

The now-full Jardim Gramacho landfill in Rio de Janeiro, Brazil, received more than 10,000 tonnes of waste per day.

\title{
Waste production must peak this century
}

Without drastic action, population growth and urbanization will outpace waste reduction, warn Daniel Hoornweg, Perinaz Bhada-Tata and Chris Kennedy.

$\mathrm{S}$ olid waste - the stuff we send down our chutes, discard at work and put on the curb every week - is a striking byproduct of civilization. The average person in the United States throws away their body weight in rubbish every month. When waste management works well, we give it little thought: out of sight and, usually, quickly out of mind. Discarded materials are collected, some are recycled or composted, and most are landfilled or incinerated. But the global view is troubling.

In the past century, as the world's population has grown and become more urban and affluent, waste production has risen tenfold.
By 2025 it will double again ${ }^{1}$. Rubbish is being generated faster than other environmental pollutants, including greenhouse gases. Plastic clogs the world's oceans and rivers, causing flooding in developing-world cities. Solid-waste management is one of the greatest costs to municipal budgets.

The waste problem is acute in emerging cities. Landfills such as Laogang in Shanghai, China; Sudokwon in Seoul; the now-full Jardim Gramacho in Rio de Janeiro, Brazil; and Bordo Poniente in Mexico City vie for the title of the world's largest. Each typically receives more than 10,000 tonnes of waste per day. Rapidly developing cities such as
Shenzhen in China are adding to the world's 2,000-plus inventory of waste incinerators. With the largest able to process more than 5,000 tonnes per day, concerns over ash disposal, air pollution and costs are rising too.

As city dwellers become richer, the amount of waste they produce reaches a limit. Wealthy societies tend to curb their waste. So as living standards around the world rise and urban populations stabilize, global solid-waste generation will peak.

Just when is difficult to predict. But by extending current socio-economic trends to 2100 , we project that 'peak waste' will not occur this century. Unless we 
$>$ reduce population growth and material consumption rates, the planet will have to bear an increasing waste burden.

\section{URBAN PROBLEM}

Solid waste is mostly an urban phenomenon. In rural communities there are fewer packaged products, less food waste and less manufacturing. A city resident generates twice as much waste as their rural counterpart of the same affluence. If we account for the fact that urban citizens are usually richer, they generate four times as much.

As urbanization increases, global solidwaste generation is accelerating. In 1900, the world had 220 million urban residents (13\% of the population). They produced fewer than 300,000 tonnes of rubbish (such as broken household items, ash, food waste and packaging) per day. By 2000, the 2.9 billion people living in cities (49\% of the world's population) were creating more than 3 million tonnes of solid waste per day. By 2025 it will be twice that - enough to fill a line of rubbish trucks 5,000 kilometres long every day.

Together, the member countries of the Organisation for Economic Co-operation and Development (OECD) are the largest waste generators, producing around 1.75 million tonnes per day. This volume is expected to increase until 2050, owing to urban population growth, and then to slowly decline, as advances in material science and technology make products smaller, lighter and more resource efficient.

Some countries generate more waste than others. Japan issues about one-third less rubbish per person than the United States, despite having roughly the same gross domestic product (GDP) per capita. This is because of higher-density living, higher prices for a larger share of imports and cultural norms. Waste quantities worldwide can also vary seasonally, by up to $30 \%$, as horticultural and food wastes fluctuate. For example, household waste volumes double in the week after Christmas in Canada.

Waste reduction and dematerialization efforts in OECD countries are countered by trends in east Asia, particularly in China.

\section{"Waste will China's solid-waste} continue to rise in the fast-growing cities of sub-Saharan Africa." generation is expected to increase from 520,550 tonnes per day in 2005 to 1.4 million tonnes per day in 2025. East Asia is now the world's fastest growing region for waste, a distinction that is likely to shift to south Asia (mainly India) in 2025, and then to sub-Saharan Africa around 2050.

As a country becomes richer, the composition of its waste changes. With more money comes more packaging, imports, electronic waste and broken toys and appliances. The wealth of a country can readily be measured, for example, by how many mobile phones it discards. Solid waste can thus be used as a proxy for the environmental impact of urbanization. Most of a material's impact is through production and use. Less than $5 \%$ stems from waste management, which includes emissions from collection trucks, landfills and incinerators.

\section{PEAK WASTE}

The rate at which solid-waste generation will rise depends on expected urban population and living standards growth and human responses. In 2012, two of us (D.H. and P.B.-T.) authored a World Bank report, What a Waste ${ }^{1}$, which estimated that global solidwaste generation would rise from more than 3.5 million tonnes per day in 2010 to more than 6 million tonnes per day in 2025. These values are relatively robust, because urban populations and per capita GDP can be well forecast for several decades.

Extending those projections to 2100 for a range of published population and GDP scenarios shows that global 'peak waste' will not happen this century if current trends continue (see 'When will waste peak?'). Although OECD countries will peak by 2050 and Asia-Pacific countries by 2075 , waste will continue to rise in the fast-growing cities of sub-Saharan Africa. The urbanization trajectory of Africa will be the main determinant of the date and intensity of global peak waste ${ }^{2}$.

Using 'business-as-usual' projections, we predict that, by 2100 , solid-waste generation rates will exceed 11 million tonnes per day - more than three times today's rate. With lower populations, denser, more resourceefficient cities and less consumption (along with higher affluence), the peak could come forward to 2075 and reduce in intensity by more than $25 \%$. This would save around 2.6 million tonnes per day.

\section{CONVERT AND DIVERT}

How can today's situation be improved? Much can be done locally to reduce waste. Some countries and cities are leading the way. San Francisco in California has a goal of 'zero waste' (100\% waste diversion by reduction and recycling) by 2020; already more than $55 \%$ of its waste is recycled or reused. The Japanese city of Kawasaki has improved its industrial processes to divert 565,000 tonnes of potential waste per year - more than all the municipal waste the city now handles. The exchange and reuse of materials connects steel, cement, chemical and paper firms into an industrial ecosystem ${ }^{3}$.

North America and Europe have tried

\section{WHEN WILL WASTE PEAK?}

Three projections to 2100 for waste generation spell very different futures. In the first Shared Socioeconomic Pathway ${ }^{9}$ scenario (SSP1), the 7-billion population is $90 \%$ urbanized, development goals are achieved, fossil-fuel consumption is reduced and populations are more environmentally conscious. SSP2 is the 'business-as-usual' forecast, with an estimated population of 9.5 million and $80 \%$ urbanization. In SSP3, 70\% of the world's 13.5 billion live in cities and there are pockets of extreme poverty and moderate wealth, and many countries with rapidly growing populations.

$$
\because \text { SSP1 } \cdots \text { SSP2 } \because S S P 3
$$
*Organisation for Economic Co-operation and Development
- Sub-Saharan Africa

- East Asia and Pacific

- Europe and central Asia

- South Asia

- Latin America and the Caribbean

Middle East and North Africa

- High-income and OECD* countries

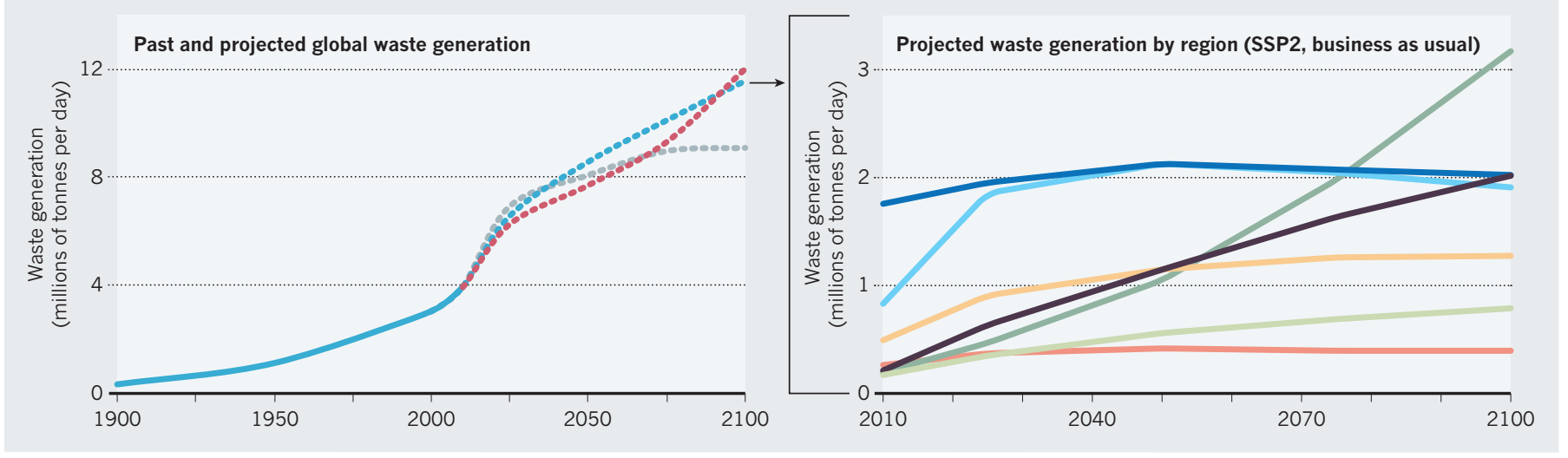


山 disposal fees, and found that as fees increase, waste generation decreases. Another tactic is to steer people to buy less with their increased wealth, and to spend more on experiential activities that require fewer resources ${ }^{4,5}$.

But greater attention to consumption and improvement in waste management is needed in rapidly urbanizing regions in developing countries, especially in Africa. Through increased education, equality and targeted economic development, as in the sustainability scenario we evaluated ${ }^{6}$ (SSP1), the global population could stabilize below 8 billion by 2075 , and urban populations shortly thereafter. Such a path reflects a move towards a society with greater urban density and less overall material consumption ${ }^{7}$. Also needed is a widespread application of 'industrial ecology' - designing industrial and urban systems to conserve materials. This begins with studies $^{8}$ of the urban metabolism - material and energy flows in cities.

Reducing food and horticultural waste is important - these waste components are expected to remain large. Construction and demolition also contribute a large fraction by mass to the waste stream; therefore, building strategies that maximize the use of existing materials in new construction would yield significant results.

The planet is already straining from the impacts of today's waste, and we are on a path to more than triple quantities. Through a move towards stable or declining populations, denser and better-managed cities consuming fewer resources, and greater equity and use of technology, we can bring peak waste forward and down. The environmental, economic and social benefits would be enormous.

Daniel Hoornweg is associate professor of energy systems at the University of Ontario Institute of Technology in Oshawa, Canada. Perinaz Bhada-Tata is a solid-waste consultant in Dubai, United Arab Emirates. Chris Kennedy is professor of civil engineering at the University of Toronto, Canada.

e-mail:daniel.hoornweg@uoit.ca

1. Hoornweg, D. \& Bhada-Tata, P. What a Waste: A Global Review of Solid Waste Management (World Bank, 2012).

2. Dyson, B. \& Chang, N. Waste Mgmt 25, 669-679 (2005).

3. Van Berkel, R., Fujita, T., Hashimoto, S. \& Fujii, M. Environ. Sci. Technol. 43, 1271-1281 (2009)

4. Ausubel, J. H. \& Waggoner, P. E. Proc. Natl Acad. Sci. USA 105, 12774-12779 (2008).

5. Eriksson, O. et al. J. Cleaner Prod. 13, 241-252 (2005).

6. Kriegler, E. Glob. Environ. Change 22, 807-822 (2012).

7. International Solid Waste Association. Globalization and Waste Management (2012)

8. Kennedy, C. A. \& Hoornweg, D. J. Indust. Ecol. 16 , 780-782 (2012)

9. International Institute for Applied Systems Analysis. SSP Database (2012); available at go.nature.com/lwp7x1.

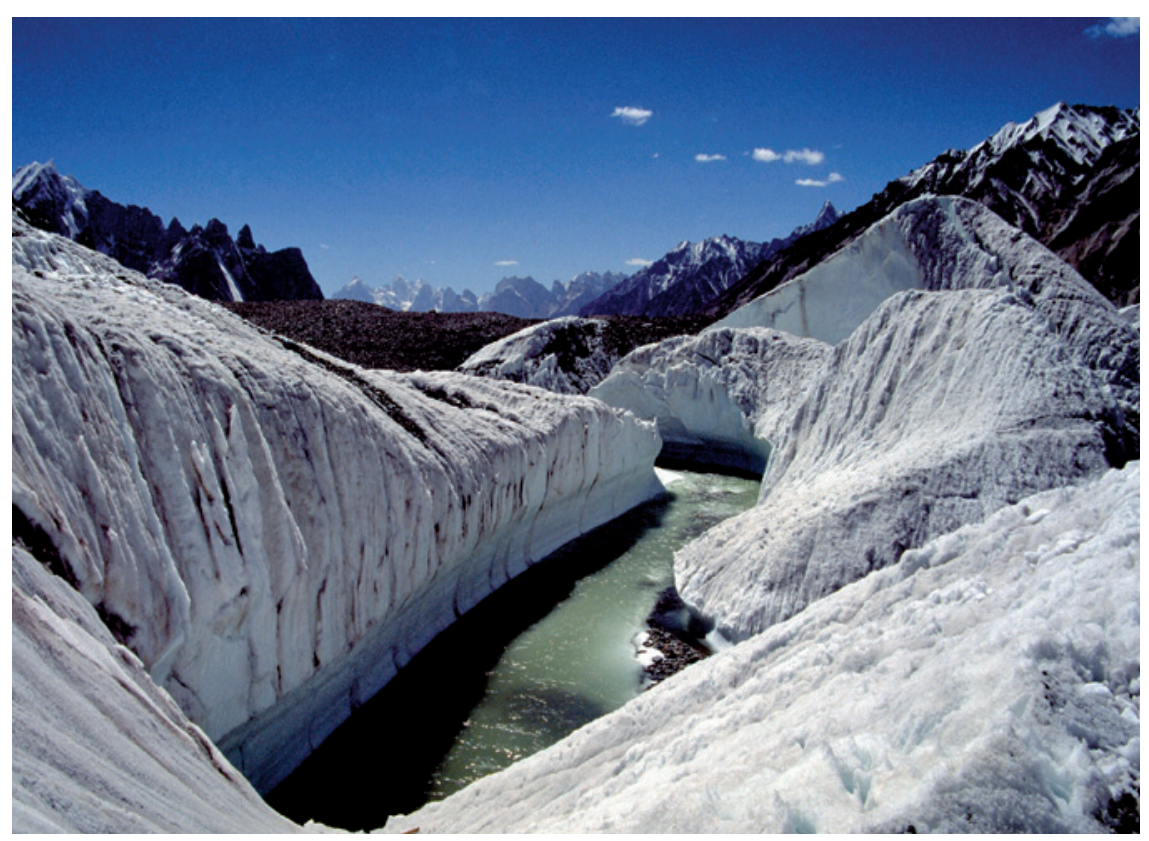

The Baltoro Glacier in the Karakoram mountain range feeds the river Indus.

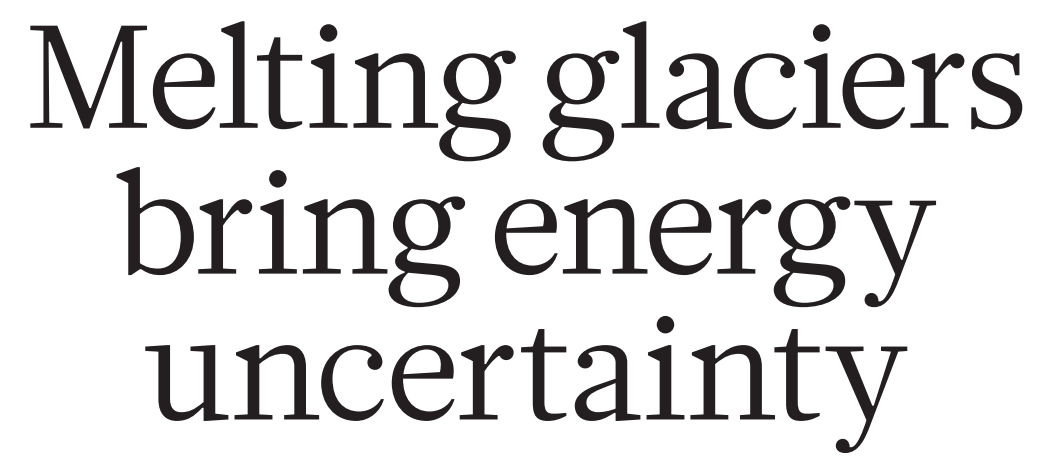

\section{Countries should work together to understand how the Himalayan thaw will affect hydroelectric energy, says Javaid R. Laghari.}

$\mathrm{R}$ unning 2,000 kilometres from east to west and comprising more than 60,000 square kilometres of ice, the Hindu Kush-Karakoram-Himalayan glaciers are a source of water for the quarter of the global population that lives in south Asia. Glaciers are natural stores and regulators of water supply to rivers, which, in turn, provide water for domestic and industrial consumption, energy generation and irrigation.

Ice cover is decreasing in this region, as for most glaciers in the world, as a result of global warming. Between 2003 and 2009, Himalayan glaciers lost an estimated 174 gigatonnes of water ${ }^{1}$, and contributed to catastrophic floods of the Indus, Ganges and Brahmaputra rivers. Pollution is accelerating the melt. An 'Asian brown cloud', formed from the 2 million tonnes of soot and dark particles released into the atmosphere every year, mostly from India and China, warms the air and surface ice ${ }^{2}$.

Seasonal meltwater serves as the main source of power for an increasing number of hydroelectric dams on the rivers served by the glaciers. But hydropower faces a difficult future in south Asia because of climatic, environmental and politicoeconomic factors. The region is starved of energy, and power shortages of up to 20 hours a day are stunting development. Importing oil and gas from the Gulf, Iran or Tajikistan is expensive or politically difficult. So countries are turning to indigenous hydroelectric power, and to other renewable energies such as solar and wind, for cheap, sustainable energy.

Hydroelectric power must play a part in south Asia's low-carbon energy future. But to be effective, governments around the Himalayas need to work together to measure and model glacier retreat, 